\title{
REVIEW
}

\section{Some Strategies for Utilization of Rice Bran Functional Lipids and Phytochemicals}

\author{
Phumon Sookwong ${ }^{1 *}$ and Sugunya Mahatheeranont ${ }^{1,2}$ \\ ${ }^{1}$ Rice and Cereal Chemistry Research Laboratory, Department of Chemistry, Faculty of Science, Chiang Mai University, Chiang Mai 50200, \\ THAILAND \\ ${ }^{2}$ Center of Excellence for Innovation in Chemistry, Faculty of Science, Chiang Mai University, Chiang Mai 50200, THAILAND
}

\begin{abstract}
Rice bran contains a great amount of functional lipids and phytochemicals including $\gamma$-oryzanols, tocotrienols, and tocopherols. However, utilization of those compounds is limited and needs some proven guidelines for better implementation. We introduce some effective strategies for the utilization of rice functional lipids, including an introduction of pigmented rice varieties for better bioactive compounds, biofortification of rice tocotrienols, plasma technology for improving rice phytochemicals, supercritical $\mathrm{CO}_{2}$ extraction of high quality rice bran oil, and an example on the development of tocotrienol-fortified foods.
\end{abstract}

Key words: rice, pigmented rice, phytochemicals, functional lipids, antioxidants

\section{Introduction}

Rice (Oryza sativa) is one of the most important crops in the world with more than half of its population consuming rice as their main energy source. More than 700 million metric tons of rice is being produced annually worldwide ${ }^{1)}$. The standard of rice production in regards to quality improvement of product in order to promote health and welfare has therefore been encouraged profoundly.

When considering nutritional values of whole rice grains, the endosperm part of white rice is made up of mainly starch (carbohydrate), whilst rice bran is a combined layer of pericarp, seed coat, nucellus, aleurone layer, and sometimes embryo, hence it contains a good source of proteins, lipids, dietary fiber, and useful minerals ${ }^{2}$. Non defatted rice bran is composed of $18-22 \%$ triacylglycerols, and the unsaponifiable lipids in rice bran are mainly comprised of $\gamma$-oryzanols, tocotrienols (T3s), and tocopherols (Tocs) ${ }^{3)}$. Other phytochemicals, which are found in a lesser concentration, include carotenoids, lecithin, long-chain alcohols, flavone, squalene, and polycosanols ${ }^{4)}$. Flavonoids in rice bran are classified as flavones, flavonols, flavanols (flavan3 -ols), flavanonols, isoflavones, and flavanones ${ }^{5)}$. The bioactive components in lipid fraction are known to have many health benefits including anti-oxidative, neuroprotective, anti-hypercholesterolemic, and anti-angiogenic properties $^{6)}$. For instance, rice bran $\gamma$-oryzanols play an impor- tant role in reducing plasma lipid and lipoprotein cholesterol concentrations ${ }^{7)}$. T3s fight cancer cells by targeting multiple cell signaling pathways ${ }^{8)}$. Polyphenols, vitamin $\mathrm{E}$ and carotenoids help prevent oxidative damage to DNA and other tissues ${ }^{9)}$.

Despite their health advantages, rice bran functional lipids are hardly consumed on a daily basis because rice bran is largely separated from white rice during commercialized polished-rice manufacturing (Fig. 1). Instead, the rice bran is separated as by-product and used wastefully as cattle and poultry feed. However, as rice bran has gained increasing interest for its health prospects, it has been encouraged to use rice bran as a natural source of functional phytochemicals for production of nutraceutical, pharmaceutical and cosmeceutical products as reported previous$\mathrm{ly}^{10-12)}$.

Therefore, in this review, we introduce some effective strategies for the utilization of rice functional lipids for health purposes. The content includes an introduction of pigmented rice varieties for better phytochemicals, bio-fortification of rice T3s, plasma technology for improving rice antioxidants, supercritical $\mathrm{CO}_{2}$ for extraction of high quality rice bran oil, and an example on the development of T3-fortified foods.

\footnotetext{
*Correspondence to: Phumon Sookwong, Rice and Cereal Chemistry Research Laboratory, Department of Chemistry, Faculty of Science, Chiang Mai University, Chiang Mai 50200, THAILAND

E-mail: phumon.s@cmu.ac.th

Accepted January 18, 2018 (received for review November 30, 2017)

Journal of Oleo Science ISSN 1345-8957 print / ISSN 1347-3352 online

http://www.jstage.jst.go.jp/browse/jos/ http://mc.manusriptcentral.com/jjocs
} 


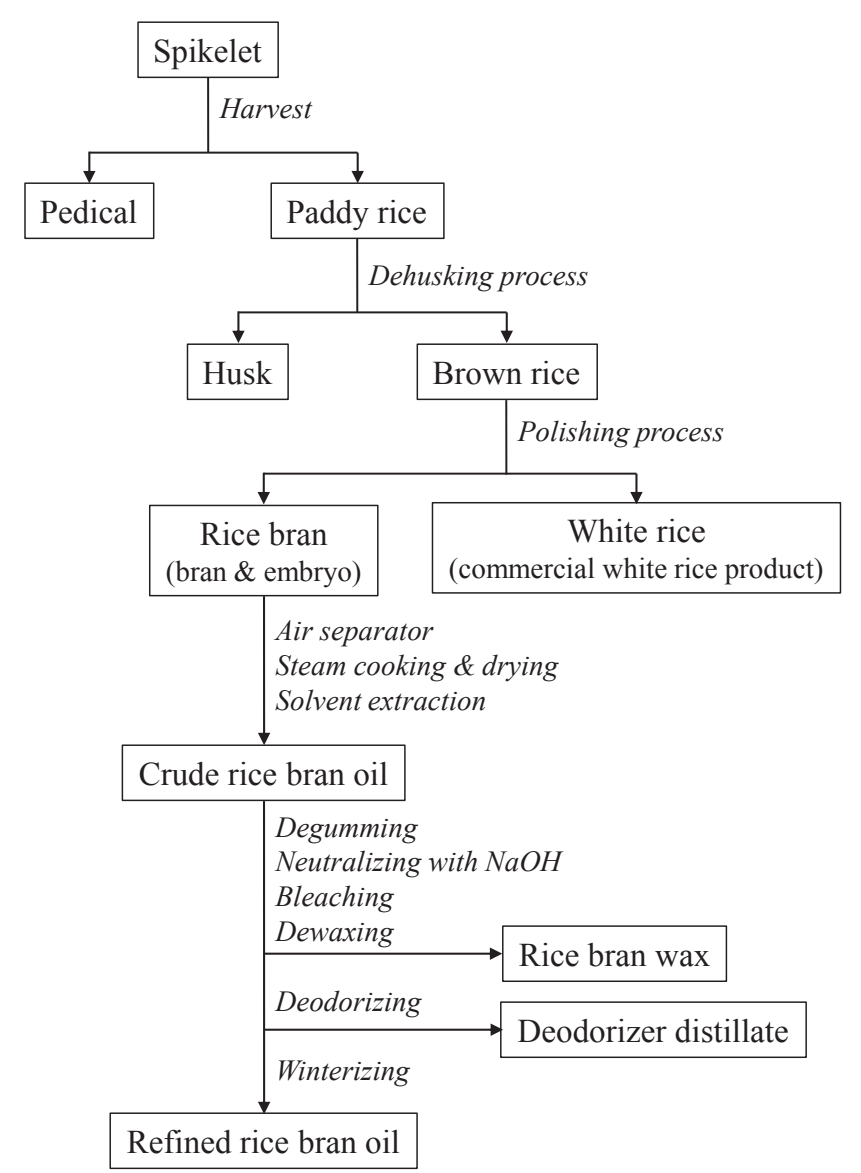

Fig. 1 Manufacturing flow chart of commercial white rice products and commercial refine rice bran oil.

\section{Pigmented rice as a superior source of physiologically active compounds}

Differences in chemical and physical characters among various kinds of rice are owned to their great diversification of rice plant variety around the world. A previous study reported different starch and sugar content as well as different physical properties in different rice samples ${ }^{13)}$. This implied that the amount and type of functional compounds in different kinds of rice differed. Variation of phenolic constituents and antioxidant properties of some varieties of Indian rice were also demonstrated ${ }^{14)}$. These findings suggested that the variety of rice was another important parameter to consider for the effective use of rice functional phytochemicals for health purposes.

Pigmented rice varieties, by definition, are rice varieties that have colors (pigments) other than the white color of ordinary white rice. The pigment is generally red, blue, brown, purple or black color appearing on the bran or/and endosperm of rice. Recently, these kinds of pigmented rice have become increasingly popular around the world, especially in Asian countries like China, India and Thailand ${ }^{15)}$. In China, pigmented rice is sometimes called forbidden rice originated from ancient China. Black rice was set aside specifically for the Emperor and the royal family, and were forbidden to regular people who were not allowed to be anywhere near the stuff.

Previous research showed that the pigments of rice mainly belonging to anthocyanin compounds consists of predominant peonidin-3-glucoside (P3G) and cyanidin3-glucoside $(\mathrm{C} 3 \mathrm{G})^{16)}$, while minor anthocyanins are cyanidin-3,5-diglucoside, cyanidin-3-rutinoside, malvidin-3-glucoside, petunidin-3-glucoside, cyanidin-dihexoside, cyanidin-3-gentiobioside, cyanidin-3-rutinoside, and cyanidin-3-sambubioside ${ }^{17-19)}$. Besides those anthocyanins, other major functional compounds are $\gamma$-oryzanols, gallic acid, protocatechuic acid, hydroxybenzoic aicd, $p$-coumaric acid, ferulic acid, sinapic acid, flavan-3-ol $(+)$ catechin and $(-)$ epicatechin, flavanols (flavan-3-ols) ${ }^{20)}$. A report by Sriseadka et al. evidenced that flavonoids in pigmented rice varieties differed from that of white rice ${ }^{21}$. Among eleven flavonoids detected, there were six flavonoids found for the first time in rice bran including taxifolin-7-O-glucoside, myricetin-7-O-glucoside, isorhamnetin-3-O-acetylglucoside, isorhamnetin-7-O-rutinoside, 5,6,3', $4^{\prime}, 5^{\prime}$-pentahydroxyflavone-7-O-glucoside, and 5, $3^{\prime}, 4^{\prime}, 5^{\prime}-$ tetrahydroxyflavanone-7-O-glucoside. The predominant glycoside derivatives of flavonoids were quercetin-3-O-glucoside, isorhamnetin-3-O-glucoside, and isorhamnetin-3-Oglucoside $\mathrm{e}^{21)}$.

A number of physiological studies regarding bioactive compounds from pigmented rice have been conducted, in which sterols, $\gamma$-oryzanols, Tocs, T3s, and phenolic compounds were extracted from pigmented rice bran ${ }^{22)}$. For instance, supplementation of highly pigmented rice bran oil could ameliorate oxidative stress and histological changes in streptozotocin-induced diabetic rats fed with high-fat diet ${ }^{23)}$. Pigmented rice bran could inhibit $\alpha$-amylase and $\alpha$-glucosidase activity, resulting in the delaying of digestion and absorption of carbohydrates ${ }^{24)}$. This could lead to the suppression of postprandial hyperglycemia in diabetic patients ${ }^{24)}$. A study by Ling et al. (2002) demonstrated that supplementation of the black rice extract to rabbits could decrease formation of atherosclerotic plaque and improve antioxidative status ${ }^{25)}$. Anti-allergic activity was also evidenced when pigmented rice bran extracts in in vitro cell assays as reduction in tumor necrosis factor (TNF) - $\alpha$, interleukin (IL) - $1 \beta$, IL-4, and IL-6 mRNA expressions was observed in RBL-2H3 cells ${ }^{26)}$. Antiinflammatory activity was also reported as a result of the red rice polar extract fraction exerting anti-inflammatory activities by inhibiting the production of TNF- $\alpha$, IL- 6 , and NO in LPS-activated macrophages ${ }^{27)}$. Pigmented rice extract could perform anti-cancer activity due to its high cytotoxicity to human hepatocellular carcinoma HepG2 cells $^{28)}$, and displayed anti-mutagenic effects against AFB1 in the Ames test ${ }^{29)}$.

On the basis of those findings, pigmented rice variety 
should therefore be considered as an attractive dietary source rich in physiologically active compounds suitable for application in health promotion.

\section{Bio-fortification of rice bran T3s}

A large number of people depend on rice as their main source of vast dietary content. For this reason, any improvements in rice quality and its production could positively affect overall living standard. Bio-fortification of nutrients in rice by mean of breeding or cultivation management plays important role for raising quality of rice products. For instance, a series of experiments conducted on breeding rice varieties for improving grain and nutritional quality was performed with the major focus driven towards the improvement of rice varieties with pro-vitamin $\mathrm{A}$, high iron and zinc content ${ }^{30)}$. On the other hand, genetically modifying processes can lead to a positive change of the required attribute in a much faster timeline. Since 1982 , there has been some efforts from scientists to develop "golden rice" which is a rice being genetically engineered to produce $\beta$-carotene (a compound being converted into vitamin $\mathrm{A}$ by the human body ${ }^{31)}$. However, the subject of study has become controversial and debated due to the negative consequences of planting and consuming golden rice, as well as human and animal safety concerns $^{32}$. Thus, cross-breeding seems to be the preferable approach since arguable issues of genetically modifying products are still unclear.

In this review, we demonstrate a model study for the biofortification of rice bran T3s. T3s belong to a lipid-soluble vitamin $\mathrm{E}$ species, and, unlike Tocs, T3s are unsaturated and possess an isoprenoid side chain. T3s have been reported for their better pharmacological potential than Tocs, which includes anti-cancer effect, anti-inflammatory activity, anti-oxidant activity, anti-diabetic activity, antihyperlipidemic activity, immunomodulatory activity, cardiovascularprotective, and anti-angiogeneis properties ${ }^{33)}$. Thus, consumption of T3-rich rice products would be an attractive way to obtain T3s and acquire their health benefits.

Since there has only been a few evidences of T3 contents in various rice bran varieties, a rapid extraction method and chromatographic determination assay for bran T3s and Toc were developed for screening T3-rich rice variety. Onestep solvent extraction with 2-propanol and normal-phase high-performance liquid chromatography (HPLC) with fluorescence detector (excitation $294 \mathrm{~nm}$, emission $326 \mathrm{~nm}$ ) could successfully separate 8 vitamin $\mathrm{E}$ isoforms within 30 minutes $^{34)}$. The analytical method required a relatively small amount of rice bran sample (50 mg) compared with those used in other studies ${ }^{35,36)}$. In addition, the method performed analysis with good selectivity and sensitivity, proving to be a suitable application for screening purposes.
According to the screening result, T3-rich variety (Milyang23) was found high in T3 content (166\% to the standard Koshihikari). Consequently, cross-breeding between the high T3-rich variety and Koshihikari was employed, and improvement of T3s was achieved in some of their $\mathrm{F}_{2}$ offspring: variation of T3 amount among $133 \mathrm{~F}_{2}$ progenies was from 60 to $200 \%$ (average content was $135 \%{ }^{37}$. It has been evidenced that biosynthesis of rice vitamin $\mathrm{E}$ (T3s and Tocs) is mainly regulated by enzymatic activities of geranylgeranyl reductase, homogentisic acid geranylgeranyl transferase (HGGT) and homogentisic acid phytyl transferase (HPT) enzymes ${ }^{38)}$. T3s and Tocs are biosynthesis from two converging pathways, the catabolism of amino acid tyrosine and isoprenoid synthesis through nonmevalonate pathway in plastids of plants. Genetic characteristics of T3-rich rice phenotype are distinguishable by means of quantitative trait locus (QTL) analysis. QTL analysis is a statistical method linking phenotypic data (trait measurements) and genotypic data (usually molecular markers or regions of chromosomes) to explain the genetic basis of variation in complex traits ${ }^{39)}$. In the T3 bio-fortification study, five putative QTLs associated with the T3 biosynthesis in their $\mathrm{F}_{2}$ progenies were detected on chromosome 1 (1 region close to RM8144 marker), chromosome 6 (2 regions close to RM3827 and RM7434 markers), and chromosome 9 (2 regions close to RM7481 and RM5786 markers), in which QTL regions performed the highest logarithm of the odds ratio (LOD) score, indicating strong enhancing effect were on chromosome 6 . In addition, major QTLs associated with Toc biosynthesis were also found on chromosome 6 , suggesting close relationship between T3 and Toc biosynthesis. Confirmation of this is represented as HGGT (enzyme responsible for T3 synthesis) and HPT (enzyme responsible for Toc synthesis) have partial structural similarity as previously reported by Collakova and DellaPenn $a^{40)}$. According to the process of biofortification, breeding scientists employ further breeding as well as confirmation of the characteristic QTL regions of latter generation of rice progenies to achieve the genetic stability needed for developing a new strain of rice variety high in T3 content.

The strategic guideline for bio-fortification of T3s is summarized in Fig. 2. Cross-breeding between two different parents having good productivity or economical advantage as well as other having desired attribute (such as high T3 content) was the bio-fortification strategy. Together with the elucidation of genetic character corresponding to desired feature would then provide a solid foundation in the development of better quality plants.

\section{Plasma technology for improving rice phytochemicals}

Rice bran is an unrivaled source of important phyto- 


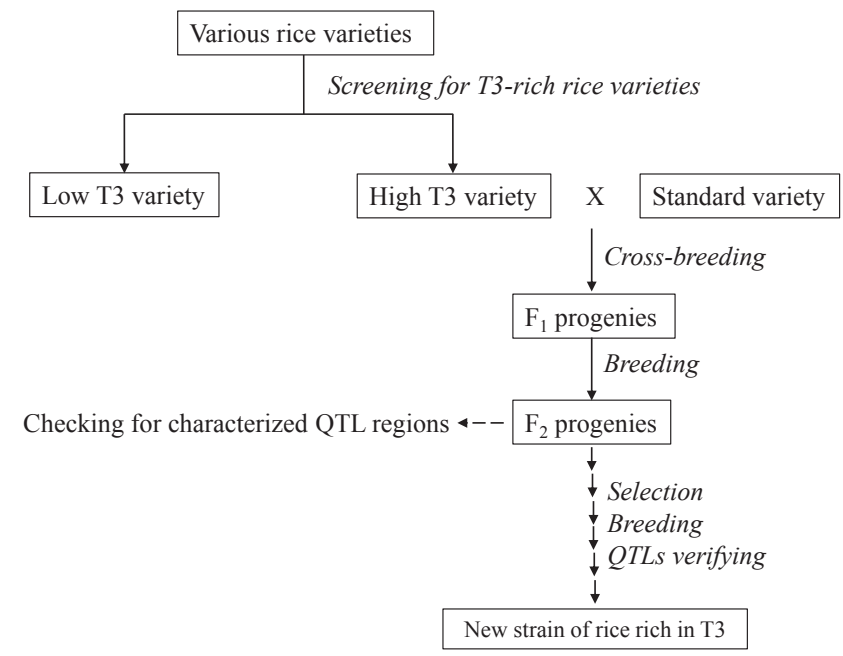

Fig. 2 The strategic guideline for bio-fortification of T3s, which includes cross-breeding between two different parents, and genetic verification of QTL regions corresponding to T3 biosynthesis.

chemicals in rice. Certainly, a technology or innovative approach that can increase or improve those phytochemical levels is required. Cross-breeding is regarded as a safe method, though it takes an extensively long time to operate and needs considerable effort. Genetically-modifying processes lead to straightforward improvements but have some safety issues and areas of controversy related to government policy, the objectivity of scientific research and publication, and the effect on the environment.

Recently, plasma technology has been introduced as a clean and environmentally-friendly technology useful in many scientific fields including biology, chemistry, physics and medicines ${ }^{41-43)}$. Plasma is one of the fourth fundamental states of matter besides solids, liquids, and gases. Plasma is a gas made of various biologically active agents, including heat, free electrons, high-energy UV photons, positive and negative ions, and uncharged particles including atoms, molecules, reactive oxygen species (ROS) and reactive nitrogen species $(\mathrm{RNS})^{44}$. Cold-plasma is generally generated by a non-equilibrium atmospheric pressure discharge. For instance, a laboratory-scale plasma jet is created by applying an electric current between two electrodes at certain radio frequencies, in which an inner electrode covered with a quartz tube centered at the axis of the outer electrode ${ }^{45}$. The cold-plasma possesses high energy and conductive properties similar to that of some metals.

In the past few years, cold-plasma has been applied in agricultural science as an effective tool for seed germination acceleration ${ }^{46)}$. A study by Ling et al. ${ }^{46)}$ showed that cold plasma treatment enhanced germination rate of rapeseed oil seeds (cultivars Zhongshuang 7 and Zhongshuang 11) even under drought stress. After plasma treatment the soluble sugar and protein contents in the rape seeds were increased, but malondialdehyde contents were decreased $^{46)}$. On the other hand, pre-germinated brown rice (PBR), a cereal product with ultimate health benefits, take advantages of chemical changes during germination for enhancing functional lipids and other compounds including $\gamma$-oryzanols, vitamin $\mathrm{E}$, vitamin $\mathrm{B} 1$, vitamin $\mathrm{B} 6$, and $\gamma$-aminobutyric acid (GABA) ${ }^{47,48)}$. A number of studies have demonstrated the health advantages of consuming PBR such as boosting the immune system, ameliorating hyperglycemia, and facilitating anxiety disorder treatment ${ }^{49-51}$. Therefore, in conjunction with the ability of plasma for enhancing seed germination and changes during germination of PBR, we hypothesize that plasma treatment may enhance the synthesis of functional phytonutrients during germination of PBR.

The previous study by Sookwong et al. has utilized argon and oxygen plasma from plasma jet instrumentation to improve nutritional value of $\mathrm{PBR}^{45}$. The gas ratio between argon and oxygen was $5: 100(\mathrm{v} / \mathrm{v})$, the tested radio frequency $(\mathrm{RF})$ power was 10 to 14 watts, the plasma exposure time was 5 to 10 seconds, the distance from plasma releaser was 5 to $8 \mathrm{~mm}$, and the electric source employed a $400 \mathrm{kHz}, 3-5 \mathrm{kV}$ voltage for operation. When plasma conditions were suitably applied, it promoted the germination rate of PBR, accelerated physical changes of the seeds (e.g., the length of root emerging from the seed was longer than non-plasma control group), and facilitated the production of functional compounds. Results from the study ${ }^{45)}$ showed that after 48 hours of seed germination, total phenolic content in plasma sample group elevated to $120 \%$ when compared with control, and GABA content of plasma sample group increased to $140 \%$ when compared with control. Moreover, another study using dielectric-barrier discharge (DBD) plasma applied onto a number of Thai rice varieties showed increasing levels of $\gamma$-oryzanols, Tocs and T3s; the main lipid antioxidants in PBR (unpublished data). Plasma treatment is understood to up-regulate metabolism and boost biosynthesis of chemicals in PBR as greater content of phytochemicals (simple phenolic compounds, pyrans, quinine, furan, and fatty acids) was detected by gas chromatography-mass spectrometry (GC-MS). Some of them can perform biological effects such as 2-methoxyphenols and 2-methoxyl-4-vimylphenol for prevention of oxidative damage of lipids and low-density lipoprotein $\mathrm{s}^{52}$ and 5-hydroxymethyl-2-furan carboxaldehyde for anti-platelet activity $^{53)}$. In addition, plasma treated PBR appeared to be softer and easy to digest since plasma was able to modify the surface properties by creating more porous structure on surface of PBR allowing water to be easily absorbed into the seeds when cooking. Furthermore, some literatures explain plasma's impact on cells insides the seeds ${ }^{54}$. The plasma energy and active particles can penetrate the seed coat and interact with the cells inside, thereby stimulating 


\section{Some Strategies for Utilization of Rice Bran Functional Lipids and Phytochemicals}

growth, altering protein structure, and enhancing enzymatic activities ${ }^{55,56)}$, resulting in higher production of beneficial metabolites. Active species including free radicals from plasma have some roles in the acceleration of seed metabolism $^{57}$.

In view of this, the relatively short time used for plasma treatment (a few seconds to a few minutes) and positive alteration (enhancement of beneficial metabolite) taken place within hours or days propose non-thermal plasma to be considered and recommended as a potential technology for rapid improvement method of PBR products rich in functional lipids and phytochemicals.

\section{Supercritical $\mathrm{CO}_{2}$ extraction of rice bran oil}

As mentioned above, rice bran (the main source of rice phytochemicals) is removed during rice polishing process for white rice commercialization. Generally, rice bran is either used cheaply as animal feeds or used as raw material for production of commercial rice bran oil (RBO). Among commercial vegetable cooking oils available, RBO have been characterized for its superior cooking, nutritional, and sensory properties despite its limited commercial use ${ }^{58,59)}$. The oil manufacturing procedure is generally a solvent-extraction based method that requires multiple steps of oil refining which employs chemicals, acids, bases, and high temperature operations $^{60)}$ (Fig. 1). The refinement process can reduce, deteriorate and degrade some bioactive compounds, thereby diminishing the nutritive value of RBO. Increasing of deodorization temperature could reduce oil stability index value as high loss of Tocs and carotenes at high temperature was observed ${ }^{61)}$. Deacidification (neutralization) process performed by high-temperature stripping may degrade significant amounts of carotenes, Tocs and T3s, thereby reducing protective power against future autoxidation of the refined oil ${ }^{62)}$. Thus, to obtain high quality rice bran oil, non-thermal or low thermal processes are considered.

Supercritical $\mathrm{CO}_{2}\left(\mathrm{SC}-\mathrm{CO}_{2}\right)$ extraction is a green separation technology for extracting sensitive or valuable compounds from complicated plants. The characteristic features of $\mathrm{SC}-\mathrm{CO}_{2}$ are non-flammable and non-toxic, so $\mathrm{SC}-\mathrm{CO}_{2}$ is approved to be safely used in food and health related products. Some previous studies reported that $\mathrm{SC}-\mathrm{CO}_{2}$ extraction could provide $\mathrm{RBO}$ with comparable extraction yield and fatty acid profile to the RBO derived from solvent extraction-based processes ${ }^{63)}$. SC- $\mathrm{CO}_{2}$ extracted $\mathrm{RBO}$ tends to have better(lower) acid value because operational condition of $\mathrm{SC}-\mathrm{CO}_{2}$ can allow deacidification of RBO by up to $97.8 \%{ }^{64)}$. Functional lipids content of RBO extracted with $\mathrm{SC}-\mathrm{CO}_{2}$ yielded higher concentration of $\gamma$-oryzanols than oil derived from hexaneSoxhlet extraction $^{63)}$. Sarmento et al. $^{65)}$ revealed high levels of Tocs and T3s in $\mathrm{SC}_{-} \mathrm{CO}_{2}$ extracted RBO, suggesting the oil to be a good source of natural vitamin E. Nowadays, $\mathrm{SC}-\mathrm{CO}_{2}$ extraction has been suggested for production of phytosterol-enriched vegetable-oil extracts ${ }^{66)}$. A study by Wang et $a l .{ }^{67)}$ reported that the extraction efficiencies of $\gamma$-oryzanols and triglycerides were 88.5 and $91.3 \%$, respectively. An evidence by Chen et al. ${ }^{68)}$ showed that $\mathrm{SC}-\mathrm{CO}_{2}$ extraction at $35 \mathrm{MPa}$ and $40^{\circ} \mathrm{C}$ for 4 hours could yield $17.5 \%$ oil with $85 \%$ extraction efficiency of $\gamma$-oryzanols.

Since antioxidants such as vitamin E(Tocs and T3s), phytosterols (mostly $\gamma$-oryzanols), and xanthophylls are functional lipids with polar parts on their structure, the $\mathrm{SC}_{-} \mathrm{SO}_{2}$ extraction rate is rather low due to its highly nonpolar attribute. The polarity of $\mathrm{SC}-\mathrm{CO}_{2}$ can be increased by adding co-solvents with polarity such as methanol, ethanol, isopropanol or water. A previous study by Sookwong et $a l .{ }^{69)}$ reported that $\mathrm{SC}-\mathrm{CO}_{2}$ extraction with $10 \mathrm{wt} \%$ ethanol as the co-solvent could improve extraction efficiency of rice bran functional lipids including Tocs, T3s, $\gamma$-oryzanols, and xanthophylls. The optimized $\mathrm{SC}-\mathrm{CO}_{2}$ operational conditions for the highest antioxidants were $60 \mathrm{~min}, 43^{\circ} \mathrm{C}$, and $37.4 \mathrm{MPa}$ with $10 \%$ ethanol as the co-solvent ${ }^{69)}$. However, excessive use of co-solvents, such as $10 \%$ to $30 \%$, could negate the extraction efficiency of oils ${ }^{70)}$. Quality of supercritically-extracted oil is easily affected by physical and chemical properties of $\mathrm{SC}-\mathrm{CO}_{2}$. Solubility (extractability) of targeted compounds can be manipulated by controlling extraction variables, such as extraction temperature, time, pressure and co-solvent. A number of studies have employed response surface methodology (RSM) and central composite design (CCD) methodology on $\mathrm{SC}-\mathrm{CO}_{2}$ extraction of RBO by combining mathematical and statistical techniques for optimizing complex parameters for the desired response. RSM together with CCD has been used for the optimization of highest oil recovery ${ }^{71}$ and highest antioxidant oil ${ }^{69)}$.

When pigmented rice bran is used as raw material, the extracted oil becomes more abundant in terms of bioactive phytochemicals. Sookwong and co-workers ${ }^{69)}$ supercritically-extracted RBOs from pigmented and non-pigmented rice bran samples, and found that the amount of bio-functional compounds was rather variety dependent and that pigmented rice bran tended to provide $\mathrm{RBO}$ with greater amounts of vitamin $\mathrm{E}$ and $\gamma$-oryzanols than non-pigmented rice bran oils (Fig. 3). Nakornriab and co-workers ${ }^{72)}$ quantified trans- $\beta$-carotene, quercetin and isorhamnetin as the typical phytochemicals found in $\mathrm{SC}-\mathrm{CO}_{2}$ extracted oils from black rice bran. These findings are in congruent with other studies suggesting pigmented rice bran as a good raw material of RBO with the finest functional constituents.

Nonetheless, instrumentation of supercritical fluid extraction apparatus may require high degree of maintenance and high operational cost. Thus, the $\mathrm{SC}-\mathrm{CO}_{2}$ oil should be considered for production of premium or high grade rice 
a) Total vitamin $\mathrm{E}$

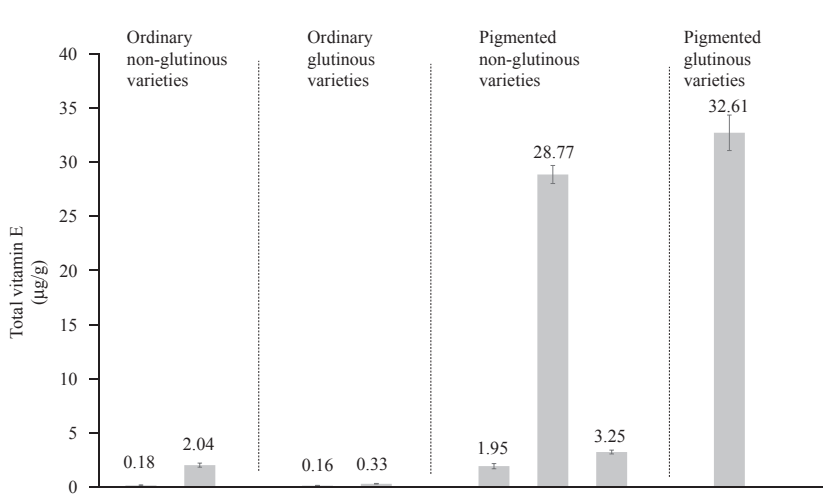

b) Total $\gamma$-oryzanols

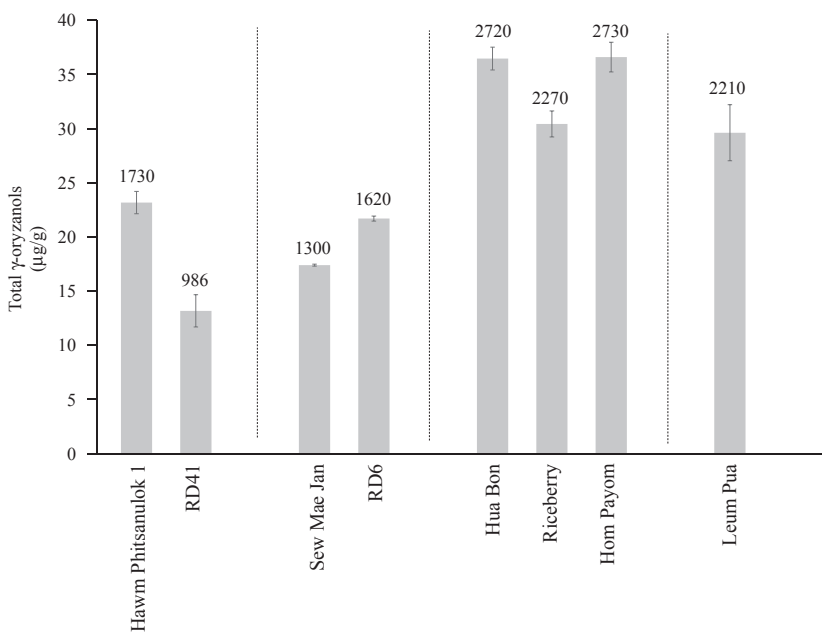

Fig. 3 The contents of total vitamin $\mathrm{E}$ (a) and total $\gamma$-oryzanols (b) in $\mathrm{CO}_{2}$-supercritically extracted $\mathrm{RBOs}^{69)}$.

bran oil that could be used in high-end commercialized products, such as cosmetics or personal care products.

\section{Development of rice bran tocol supplementary products}

Tocols refer to a collective name of lipid-soluble vitamin $\mathrm{E}$ that include both Tocs and T3s. Toc are famous species, found in many plants such as wheat, sunflower seed, almond, and olive. T3s have been in focus due to their superior physiological properties ${ }^{73)}$. However, in nature T3s are specifically found only in certain kinds of plants (e.g., rice bran), implying that an average daily intake amount of T3s is limited. A report by Sookwong et al. ${ }^{74)}$ demonstrated that the estimated daily T3 intake of Japanese population is around 1.8-2.0 mg/day/person, which is comparatively small compared with those of Toc being reported as 8-10 mg/day/person. Therefore, development of vitamin E supplementary products, especially $\mathrm{T} 3 \mathrm{~s}$, is required to achieve their effectiveness of health benefits.

The concept of modern agribusiness worlds tends to make full utilization of agricultural products with minimal waste. Deodorizer distillate (a fraction of volatiles being separated in refining processes) is a by-product of RBO manufacturing (Fig. 1). It contains a considerable amount of vitamin $\mathrm{E}$ (1.3\% of T3s and $1.7 \%$ of Tocs) compared to that of refined $\mathrm{RBO}(0.03 \%$ of $\mathrm{T} 3 \mathrm{~s}$ and $0.01 \%$ of Tocs $)$, suggesting that RBO deodorizer distillate is an attractive starter material of natural T3s and Tocs for the development of dietary supplement products.

Useful technologies for increasing tocol concentration in RBO deodorizer distillate include molecular distillation, and anion-exchange resin ${ }^{75,76)}$. Hiromori and co-workers ${ }^{76)}$ developed a simple low-temperature purification process of rice bran vitamin $\mathrm{E}$ from $\mathrm{RBO}$ deodorizer distillate encompassing esterification with a cation-exchange resin catalyst, the adsorption of vitamin $\mathrm{E}$ onto an anion-exchange resin, and its desorption from the resin. The process had higher overall recovery ratio and mass fraction of the product $(76 \%$ and $51 \mathrm{wt} \%)$ than those of molecular distillation method $(50 \% \text { and } 35 \mathrm{wt} \%)^{77)}$. The tocol concentrate can be further used for production of dietary supplement from rice extract without further purification.

Another approach for utilization of RBO deodorizer distillate is to mix it with animal feed. Supplementation of the animal feed with deodorizer distillate has been recommended for raising animals as it would be beneficial to their health and, also meat quality for human consumption $^{78)}$. Feeding broilers (egg-laying hens) with standard feed supplemented with RBO deodorizer distillate (2-4\%, $\mathrm{w} / \mathrm{w})$ resulted in high accumulation of Tocs and T3s in eggs $^{79)}$. In the groups fed with RBO deodorizer distillate, the content of T3s and Tocs were elevated by up to $0.6 \mathrm{mg}$ T3s/egg and $7.2 \mathrm{mg}$ Tocs/egg while those of control eggs were $0.08 \mathrm{mg}$ T3s/egg and $1.7 \mathrm{mg}$ Tocs/egg ${ }^{79)}$. Similarly, higher accumulation of T3s and Tocs were also investigated in another supplementation study investigating on edible broiler parts (breast, thigh, and liver), in which broiler feed had been added with RBO deodorizer distillate (Sookwong, P.; Nakagawa, K.; Miyazawa, T., unpublished data). The results were in agreement with the study by other reserachers ${ }^{80)}$ who reported that 0.4 and $5.5 \mathrm{mg} / \mathrm{kg}$ of T3s was incorporated in breast and thigh, respectively, after palm oil supplementation (60 mg T3s/kg feed). The findings suggested that supplementation of animal feed with RBO deodorizer distillate was a cost-effective and proven method for enhancing nutritional value in animal products.

\section{Perspective and conclusions}

Rice bran functional lipids and phytochemicals are known for their health benefits, though the utilization of 
these compounds are currently underperformed. This is partly due to lack of proven strategies and reliable guidelines for their effective use. In this review, some strategies for the utilization of rice functional compounds are proposed. Pigmented rice varieties were introduced and recommended as healthy rice due to their considerable content of antioxidants and bio-active compounds. It is beneficial as cooking rice for consumption or used as a starting material for manufacturing of nutraceutical or functional food products. The bio-fortification of T3s in rice plants by means of screening $\mathrm{T} 3$-rich rice varieties, classic cross-breeding and genetic verification would bring solid foundation in the improvement of $\mathrm{T} 3$ without controversial safety issues of genetically modifying processes. Plasma technology is a promising and innovative method that could positively activate biosynthesis of functional lipids and phytochemicals during germination period of PBR. The improvement of PBR using plasma technology is considered economical due to its relatively short operation time. $\mathrm{SC}-\mathrm{CO}_{2}$ extraction is a non-thermal separation technology that is very useful for the production of the highest quality RBO, in which sensitive and valuable compounds in rice bran are minimally destroyed. In addition, supplementation of animal feed with RBO deodorizer distillate, a byproduct of $\mathrm{RBO}$ production but rich in vitamin $\mathrm{E}$, is an economical effective method for improving meat quality and nutritional value in animal products.

\section{Acknowledgements}

This work was financially and technically supported by Dr. Bruno Werdelmann Foundation, the Functional Food Research Center for Well-being (Chiang Mai University), the Higher Education Research Promotion and National Research University Project of Thailand, and the Center of Excellence for Innovation in Chemistry (PERCH-CIC), Office of the Higher Education Commission, Ministry of Education, Thailand.

\section{References}

1) Paddy rice production worldwide in 2017 [Internet]. New York, NY: Statista, Inc. https://www.statista.com/ statistics/255937/leading-rice-producers-worldwide/ Accessed 9 January 2018.

2) Oliveira, M.S.; Feddern, V.; Kupsk, L.; Cipolatti, E.P.; Furlong, E.B.; Soares, L.A.S. Changes in lipid, fatty acids and phospholipids composition of whole rice bran after solid-state fungal fermentation. Bioresour. Technol. 102, 8335-8338 (2011).

3) Chen, M.-H.; Bergman, C.J. A rapid procedure for analysing rice bran tocopherol, tocotrienol and $\gamma$-oryzanol contents. J. Food Compos. Anal. 18, 139-151(2005).

4) Zhang, M.W.; Zhang, R.F.; Zhang, F.X.; Liu, R.H. Phenolic profiles and antioxidant activity of black rice bran of different commercially available varieties. $J$. Agric. Food Chem. 58, 7580-7587 (2010).

5) Goufo, P.; Trindade, H. Rice antioxidants: phenolic acids, flavonoids, anthocyanins, proanthocyanidins, tocopherols, tocotrienols, $\gamma$-oryzanol, and phytic acid. Food Sci. Nutr. 2, 75-104(2014).

6) Sohail, M.; Rakha, A.; Butt, M.S.; Iqbal, M.J.; Rashid, S. Rice bran nutraceutics: A comprehensive review. Crit. Rev. Food Sci. 57, 3771-3780(2017).

7) Wilson, T.A.; Nicolosi, R.J.; Woolfrey, B.; Kritchevsky, D. Rice bran oil and oryzanol reduce plasma lipid and lipoprotein cholesterol concentrations and aortic cholesterol ester accumulation to a greater extent than ferulic acid in hypercholesterolemic hamsters. J. Nutr. Biochem. 18, 105-112 (2007).

8) Kannappan, R.; Gupta, S.C.; Kim, J.H.; Aggarwal, B.B. Tocotrienols fight cancer by targeting multiple cell signaling pathways. Genes Nutr. 7, 43-52 (2012).

9) Bouayed, J.; Bohn, T. Exogenous antioxidants-Doubleedged swords in cellular redox state: Health beneficial effects at physiologic doses versus deleterious effects at high doses. Oxid. Med. Cell Longev. 3, 228-237 (2010).

10) Ammar, H.O.; Al-Okbi, S.Y.; Mostafa, D.M.; Helal, A.M. Rice bran oil: Preparation and evaluation of novel liquisolid and semisolid formulations. Int. J. Pharm. Compd. 16, 516-523(2012).

11) Al-Okbi, S.Y.; Hussein, A.M.S.; Hamed, I.M.; Mohamed, D.A.; Helal, A.M. Chemical, rheological, sensorial and functional properties of gelatinized corn-rice bran flour composite corn flakes and tortilla chips. J. Food Process. Preserv. 38, 83-89 (2014).

12) Al-Okbi, S.Y.; Hamed, I.M.; Mohamed, D.A.; Hussein, A.M.S.; Helal, A.M. Physiochemical, sensory and biological properties of wheat-rice bran composite biscuits, crackers and pasta. Res. J. Pharm., Biol. Chem. Sci. 7, 1201-1214(2016).

13) Omar, K.A.; Salih, B.M.; Abdulla, N.Y.; Hussin, B.H.; Rassul, S.M. Evaluation of starch and sugar content of different rice samples and study their physical properties. Indian J. Nat. Sci. 6, 11084-11093(2016).

14) Biswas, S.; Sircar, D.; Mitra, A.; De, B. Phenolic constituents and antioxidant properties of some varieties of Indian rice. Nutr. Food Sci. 41, 123-135 (2011).

15) Kong, L.; Wang, Y.; Cao, Y. Determination of myo-inositol and D-chiro-inositol in black rice bran by capillary electrophoresis with electrochemical detection. $J$. Food Compos. Anal. 21, 501-504 (2008).

16) Pitija, K.; Nakornriab, M.; Sriseadka, T.; Vanavichit, A.; Wongpornchai, S. Anthocyanin content and antioxidant capacity in bran extracts of some Thai black rice 
varieties. Int. J. Food Sci. Tech. 48, 300-308(2013).

17) Chen, X.Q.; Nagao, N.; Itani, T.; Irifune, K. Anti-oxidative analysis, and identification and quantification of anthocyanin pigments in different coloured rice. Food Chem. 135, 2783-2788(2012).

18) Hiemori, M.; Koh, E.; Mitchell, A.E. Influence of cooking on anthocyanins in black rice (Oryza sativa L. japonica var. SBR). J. Agric. Food Chem. 57, 1908$1914(2009)$.

19) Hao, J.; Zhu, H.; Zhang, Z.; Yang, S.; Li, H. Identification of anthocyanins in black rice (Oryza sativa L.) by UPLC/QTOF-MS and their in vitro and in vivo antioxidant activities. J. Cereal Sci. 64, 92-99(2015).

20) Samyor, D.; Das, A.B.; Deka, S.C. Pigmented rice a potential source of bioactive compounds: a review. Int. J. Food Sci. Tech. 52, 1073-1081 (2017).

21) Sriseadka, T.; Wongpornchai, S.; Rayanakorn, M. Quantification of flavonoids in black rice by liquid chromatography-negative electrospray ionization tandem mass spectrometry. J. Agric. Food Chem. 60, 1172311732 (2012).

22) Samad, N. Rice bran oil prevents neuroleptic-induced extrapyramidal symptoms in rats: possible antioxidant mechanisms. J. Food Drug Anal. 23, 370-375(2015).

23) Posuwan, J.; Prangthip, P.; Leardkamolkarn, V.; Yamborisut, U.; Surasiang, R.;Charoensiri, R.; Kongkachuichai, R. Long-term supplementation of high pigmented rice bran oil(Oryza sativa L.) on amelioration of oxidative stress and histological changes in streptozotocin-induced diabetic rats fed a high fat diet; Riceberry bran oil. Food Chem. 138, 501-508(2013).

24) Boue, S.M.; Daigle, K.W.; Chen, M.; Cao, H.; Heiman, M.L. Antidiabetic potential of purple and red rice (Oryza sativa L.) bran extracts. J Agric. Food Chem. 64, 5345-5353 (2016).

25) Ling, W.H.; Wang, L.L.; Ma, J. Supplementation of the black rice outer layer fraction to rabbits decreases atherosclerotic plaque formation and increases antioxidant status. J. Nutr. 132, 20-26 (2002).

26) Choi, S.P.; Kang, M.; Koh, H.J.; Nam, S.H.; Friedman, M. Antiallergic activities of pigmented rice bran extracts in cell assays. J. Food Sci. 72, S719-S726 (2007).

27) Limtrakul, P.; Yodkeeree, S.; Pitchakarn, P.; Punfa, W. Anti-inflammatory effects of proanthocyanidin-rich red rice extract via suppression of MAPK, AP-1 and NF-кB pathways in Raw 264.7 macrophages. Nutr. Res. Pract. 10, 251-258(2016).

28) Banjerdpongchai, R.; Wudtiwai, B.; Sringarm, K. Cytotoxic and apoptotic-inducing effects of purple rice extracts and chemotherapeutic drugs on human cancer cell lines. Asian Pac. J. Cancer Prev. 14, 6541-6548 (2013).

29) Punvittayagul, C.; Sringarm, K.; Chaiyasut, C.; Wongpoomchai, R. Mutagenicity and antimutagenicity of hydrophilic and lipophilic extracts of Thai Northern purple rice. Asian Pac. J. Cancer Prev. 15, 9517$9522(2014)$.

30) Brar, D.S.; Virk, P.S.; Grewal, D.; Slamet-Loedin, I.; Fitzgerald, M.; Khush, G.S. Breeding rice varieties with improved grain and nutritional quality. Qual. Assur. Saf. Crop. 4, 136-158(2012).

31) Ye, X.; Al-Babili, S,; Klöti, A.; Zhang, J.; Lucca, P.; Beyer, P.; Potrykus, I. Engineering the provitamin A (betacarotene) biosynthetic pathway into (carotenoid-free) rice endosperm. Science 287, 303-305 (2000).

32) Bawa, A.S.; Anilakumar, K.R. Genetically modified foods: safety, risks and public concerns - a review. $J$. Food Sci. Technol. 50, 1035-1046 (2013).

33) Ahsan, H.; Ahad, A.; Iqbal, J.; Siddiqui, W.A. Pharmacological potential of tocotrienols: a review. Nutr. Metab. (Lond) 11, 52(2014).

34) Sookwong, P.; Nakagawa, K.; Murata, K.; Kojima, Y.; Miyazawa, T. Quantitation of tocotrienol and tocopherol in various rice brans. J. Agric. Food Chem. 55, 461466 (2007).

35) Huang, Y.-P.; Lai, H.-M. Bioactive compounds and antioxidative activity of colored rice bran. J. Food Drug Anal. 24, 564-574(2016).

36) Yu, S.; Nehus, Z.T.; Badger, T.M.; Fang, N. Quantification of vitamin $\mathrm{E}$ and $\gamma$-oryzanol components in rice germ and bran. J. Agric. Food Chem. 55, 7308-7313 (2007).

37) Sookwong, P.; Murata, K.; Nakagawa, K.; Shibata, A.; Kimura, T.; Yamaguchi, M.; Kojima, Y.; Miyazawa, T. Cross-fertilization for enhancing tocotrienol biosynthesis in rice plants and QTL analysis of their $\mathrm{F}_{2}$ progenies. J. Agric. Food Chem. 57, 4620-4625 (2009).

38) Schneider, C. Chemistry and biology of vitamin E. Mol. Nutr. Food Res. 49, 7-30(2005).

39) Kearsey, M.J. The principles of QTL analysis (a minimal mathematics approach). J. Exp. Bot. 49, 16191623 (1998).

40) Collakova, E.; DellaPenna, D. Isolation and functional analysis of homogentisate phytyltransferase from Synechocystis sp. PCC 6803 and Arabidopsis. Plant Physiol. 127, 1113-1124(2001).

41) Chu, P.K.; Chen, J.Y.; Wang, L.P.; Huang, N. Plasmasurface modification of biomaterials. Mater. Sci. Eng. $R$ Rep. 36, 143-206 (2002).

42) Winter, T.; Winter, J.; Polak, M.; Kusch, K.; Mäder, U.; Sietmann, R.; Ehlbeck, J.; van Hijum, S.; Weltmann, K.D.; Hecker, M.; Kusch, H. Characterization of the global impact of low temperature gas plasma on vegetative microorganisms. Proteomics 11, 3518-3530 (2011).

43) Isbary, G.; Shimizu, T.; Li, Y.F.; Stolz, W.; Thomas, H.M.; Morfill, G.E.; Zimmermann, J.L. Cold atmospheric plasma devices for medical issues. Expert Rev. Med. 
Devic. 10, 367-377(2013).

44) Moisan, M.; Barbeau, J.; Moreau, S.; Pelletier, J.; Tabrizian, M.; Yahia, L.H. Low-temperature sterilization using gas plasmas: a review of the experiments and an analysis of the inactivation mechanisms. Int. $J$. Pharm. 226, 1-21 (2001).

45) Sookwong, P.; Yodpitak, S.; Doungkaew, J.; Jurithayo, J.; Boonyawan, D.; Mahatheeranont, S. Application of oxygen-argon plasma as a potential approach of improving the nutrition value of pre-germinated brown rice. J. Food Nutr. Res. 2, 946-951 (2014).

46) Ling, L.; Jiangang, L.; Minchong, S.; Chunlei, Z.; Yuanhua, D. Cold plasma treatment enhances oilseed rape seed germination under drought stress. Sci. Rep. 5, $13033(2015)$.

47) Patil, S.B.; Khan, M.K. Germinated brown rice as a value added rice product: A review. J. Food Sci. Technol. 48, 661-667(2011).

48) Yodpitak, S.; Sookwong, P.; Akkaravessapong, P.; Wongpornchai, S. Changes in antioxidant activity and antioxidative compounds of brown rice after pre-germination. J. Food Nutr. Res. 1, 132-137 (2013).

49) Wu, F.; Chen, H.; Yang, N.; Duan, X.; Jin, Z.; Xu, X. Germinated brown rice enhances antioxidant activities and immune functions in aged mice. Cereal Chem. 90, 601-607 (2013).

50） Torimitsu, M.; Nagase, R.; Yanagi, M.; Homma, M.; Sasai, Y.; Ito, Y.; Hayamizu, K.; Nonaka, S.; Hosono, T.; Kise, M.; Seki, T.; Ariga, T. Replacing white rice with pre-germinated brown rice mildly ameliorates hyperglycemia and imbalance of adipocytokine levels in type 2 diabetes model rats. J. Nutr. Sci. Vitaminol. (Tokyo) 56, 287-292 (2010) .

51) Mamiya, T.; Kise, M.; Morikawa, K.; Aoto, H.; Ukai, M.; Noda, Y. Effects of pre-germinated brown rice on depression-like behavior in mice. Pharmacol. Biochem. Behav. 86, 62-67 (2007).

52) Jeong, J.B.; Jeong, H.J. 2-Methoxy-4-vinylphenol can induce cell cycle arrest by blocking the hyper-phosphorylation of retinoblastoma protein in benzo [a]pyrene-treated NIH3T3 cells. Biochem. Biophys. Res. Commun. 400, 752-757 (2010).

53) Pyo, M.K.; Jin, J.L.; Koo, Y.K.; Yun-Choi, H.S. Phenolic furan type compounds isolated from Gastrodia elata and their anti-platelet effects. Arch. Pharm. Res. 27, 381-385 (2004).

54） Zhou, R.; Zhou, R.; Zhang, X.; Zhuang, J.; Yang, S.; Bazaka, K.; (Ken) Ostrikov, K. Effects of atmosphericpressure $\mathrm{N}_{2}, \mathrm{He}$, Air, and $\mathrm{O}_{2}$ microplasmas on mung bean seed germination and seedling growth. Sci. Rep. 6, 32603 (2016).

55）Volin, J.C.; Denes, F.S.; Young, R.A.; Park, S.M.T. Modification of seed germination performance through cold plasma chemistry technology. Crop Sci. 40, 1706-1718
(1999).

56) Henselová, M.; Slováková, L.; Martinka, M.; Zahoranová, A. Growth, anatomy and enzyme activity changes in maize roots induced by treatment of seeds with low-temperature plasma. Biologia 67, 490-497 (2012).

57) Stoffels, E.; Sakiyama, Y.; Graves, D.B. Cold atmospheric plasma: charged species and their interactions with cells and tissues. IEEE T. Plasma Sci. 36, 14411451 (2008).

58) Hu, W.; Wells, J.H.; Shin, T.S.; Godber, J.S. Comparison of isopropanol and hexane for extraction of vitamin $\mathrm{E}$ and oryzanols from stabilized rice bran. J. Am. Oil Chem. Soc. 73, 1653-1656 (1996).

59) McCaskill, D.R.; Zhang, F. Use of rice bran oil in foods. Food Technol. 53, 50-52 (1999).

60) Bruscatto, M.H.; Zambiazi, R.C.; Sganzerla, M.; Pestana, V.R.; Otero, D.; Lima, R.; Paiva, F. Degradation of tocopherols in rice bran oil submitted to heating at different temperatures. J. Chromatogr. Sci. 47, 762-765 (2009).

61) Zulkurnain, M.; Lai, O.M.; Tan, S.C.; Abdul Latip, R.; Tan, C.P. Optimization of palm oil physical refining process for reduction of 3-monochloropropane-1,2-diol (3-MCPD) ester formation. J. Agric. Food Chem. 61,3341-3349 (2013).

62) Zulkurnain, M.; Lai, O.M.; Latip, R.A.; Nehdi, I.A.; Ling, T.C.; Tan, C.P. The effects of physical refining on the formation of 3-monochloropropane-1,2-diol esters in relation to palm oil minor components. Food Chem. 135, 799-805 (2012).

63) Kuk, M.S.; Dowd, M.K. Supercritical $\mathrm{CO}_{2}$ extraction of rice bran. J. Am. Oil Chem. Soc. 75, 623-628(1998).

64) Chen, C.-R.; Wang, C.-H.; Wang, L.-Y.; Hong, Z.-H.; Chen, S.-H.; Ho, W.-J.; Chang, C.-M.J. Supercritical carbon dioxide extraction and deacidification of rice bran oil. J. Supercrit. Fluid 45, 322-331 (2008).

65) Sarmento, C.M.P.; Ferreira, S.R.S.; Hense, H. Supercritical fluid extraction (SFE) of rice bran oil to obtain fractions enriched with tocopherols and tocotrienols. Braz. J. Chem. Eng. 23, 243-249 (2006).

66) Dunford, N.T.; King, J.W. Phytosterol enrichment of rice bran oil by a supercritical carbon dioxide fractionation technique. J. Food Sci. 65, 1395-1399 (2000).

67) Wang, C.-H.; Chen, C.-R.; Wu, J.-J.; Wang, L.-Y.; Chang, C.-M.J.; Ho, W.-J. Designing supercritical carbon dioxide extraction of rice bran oil that contain oryzanols using response surface methodology. J. Sep. Sci. 31, 1399-1407 (2008).

68) Chen, C.-R.; Wang, L.-Y.; Wang, C.-H.; Ho, W.-J.; Chang, C.-M.J. Supercritical carbon dioxide extraction of rice bran oil and column partition fractionation of $\gamma$-oryzanols. Sep. Purif. Technol. 61, 358-365 (2008).

69) Sookwong, P.; Suttiarporn, P.; Boontakham, P.; Seek- 
how, P.; Wangtueai, S.; Mahatheeranont, S. Simultaneous quantification of vitamin $\mathrm{E}, \boldsymbol{\gamma}$-oryzanols and xanthophylls from rice bran essences extracted by supercritical $\mathrm{CO}_{2}$. Food Chem. 211, 140-147 (2016).

70) Seo, J.S.; Burri, B.J.; Quan, Z.; Neidlinger, T.R. Extraction and chromatography of carotenoids from pumpkin. J. Chromatogr. A 1073, 371-375 (2005).

71) Ahmad, S.W.; Javed, F.; Ahmad, S.; Akram, M; Rehman, A. Parametric optimization of rice bran oil extraction using response surface methodology. Pol. J. Chem. Technol. 18, 103-109(2016).

72) Nakornriab, M.; Sriseadka, T.; Wongpornchai, S. Quantification of carotenoid and flavonoid components in brans of some Thai rice cultivars using supercritical fluid extraction and high-performance liquid chromatography-mass spectrometry. J. Food Lipids 15, 488$503(2008)$.

73) Sen, C.K.; Khanna, S.; Roy, S. Tocotrienols in health and disease: the other half of the natural vitamin $\mathrm{E}$ family. Mol. Aspects Med. 28, 692-728(2007).

74) Sookwong, P.; Nakagawa, K.; Yamaguchi, Y.; Miyazawa, T.; Kato, S.; Kimura, F.; Miyazawa, T. Tocotrienol distribution in foods: estimation of daily tocotrienol intake of Japanese population. J. Agric. Food Chem. 58, 3350-3355 (2010).
75) Martins, P.F.; Batistella, C.B.; Maciel-Filho, R.; WolfMaciel, M.R. Comparison of two different strategies for tocopherols enrichment using a molecular distillation process. Ind. Eng. Chem. Res. 45, 753-758(2006).

76) Hiromori, K.; Shibasaki-Kitakawa, N.; Nakashima, K.; Yonemoto, T. Novel simple process for tocopherols selective recovery from vegetable oils by adsorption and desorption with an anion-exchange resin. Food Chem. 194, 1-5 (2016).

77) Maarasyid, C.; Muhamad, I.I.; Supriyanto, E. Potential source and extraction of vitamin $\mathrm{E}$ from palm-based oils: a review. J. Teknol. 69, 43-50 (2014).

78) Hussain Sherazi, S.T.; Mahesar, S.A.; Sirajuddin. Vegetable oil deodorizer distillate: a rich source of the natural bioactive components. J. Oleo Sci. 65, 957-966 (2016).

79) Sookwong, P.; Nakagawa, K.; Nakajima, S.; Amano, Y.; Toyomizu, M.; Miyazawa, T. Tocotrienol content in hen eggs: its fortification by supplementing the feed with rice bran scum oil. Biosci. Biotechnol. Biochem. 72, 3044-3047 (2008).

80) Kang, K.R.; Cherian, G.; Sim, J.S. Dietary palm oil alters the lipid stability of polyunsaturated fatty acids modified poultry products. Poultry Sci. 80, 228-234 (2001). 